ENSAYO

\title{
EL DINAMISMO, LA ESPERANZA, LOS LÍMITES: EL PAPA JUAN PABLO II EN EL SIGLO XX*
}

\section{Joaquín Fermandois}

\begin{abstract}
Al pensar las relaciones entre el Papa Juan Pablo II y la historia de nuestra época surgen varias dimensiones. Una de ellas es que se trata de un Papa "muy histórico". Ello porque fue "muy polaco"; nació en un país que, como pocos, resume gran parte de la historia del siglo XX y llevó muchas de sus experiencias a Roma al ser elegido Pontífice, aunque no en el sentido estrecho. Por otro lado, el nuevo Papa debió enfrentar el desafío de una crisis de la Iglesia, en parte consecuencia de haber querido asumir con mucho optimismo la historia secular en la época del Concilio; se trataba de ver qué significaba eso en el mundo del último cuarto del siglo. La caída del comunismo - ¿y en qué medida Juan Pablo II fue una de sus causas?- - como también el desafío del fundamentalismo islámico constituyen aspectos de la relación entre el Papa y la historia de nuestra época. Los principales rasgos del pontificado podrían caracterizarse como el haber asumido un nuevo liderazgo que renovó a la Iglesia, ser parte de una toma de conciencia acerca de lo permanente de la religión en la historia del ser humano y dar un nuevo estilo a la respuesta ante el desafío moderno de la secularización.
\end{abstract}

JoAquín Fermandois. Profesor de historia contemporánea, Pontificia Universidad Católica de Chile. Miembro de número de la Academia Chilena de la Historia.

* Versión ampliada de artículo aparecido en “Artes y Letras”, El Mercurio, 3 de abril de 2005.

Estudios Públicos, 101 (verano 2006). 
巨1 16 de octubre de 1978, al divisarse el humo blanco que emergía desde los techos de El Vaticano, se supo que ya había un nuevo Papa. Cuando poco después se anunció el nombre del recién elegido por el Colegio Cardenalicio, corrió un murmullo de incredulidad que la televisión por satélite hizo resonar por todo el planeta. “¿Polaco?, ¿cómo dijo que se llamaba?” “Tan joven”, 57 años, se decían periodistas y fieles. Era Karol Wojtyla, cardenal primado de Cracovia. Al dar la primera bendición urbi et orbi, se apartó del protocolo tradicional y dirigió unas palabras en italiano a la multitud que lo vitoreaba. El mismo toque personal lo distinguió en la ceremonia de inauguración (Papa lo era desde el momento en que aceptó oralmente, en respuesta a la pregunta “¿Aceptas?”). Su nuevo nombre fue el que todos adivinaban, Juan Pablo II, una manera de honrar al titular del breve pontificado anterior, Albino Luciani, que había tomado el nombre compuesto de Juan Pablo I. Seguiría un largo e influyente pontificado que llegó a su fin hace un año.

\section{Un nuevo estilo en tiempos de incertidumbre}

El año que siguió el pueblo católico y el resto del mundo comenzaron a verse seducidos y maravillados por su personalidad activa y adaptada creativamente a los medios de comunicación modernos. Los viajes, las conferencias, las conversaciones, los desplazamientos dentro de Italia, la rápida puesta en escena de un nuevo punto de referencia mundial, no sólo como autoridad católica, no sólo como un líder espiritual más allá del catolicismo y del cristianismo, sino que también como estadista, fueron una de las sorpresas en los tiempos en que se empezaba a hablar de la crisis intrínseca de liderato en la sociedad moderna. A los católicos no les cupo duda de que el nuevo pontificado significaría una profunda renovación de la Iglesia, a la que la crisis de la modernidad le había tocado en sus fibras más íntimas.

Al hablar del vínculo entre el pontificado de Juan Pablo II y su momento histórico hay que considerar varias dimensiones. Una de ellas es su relación con la historia moderna del mismo catolicismo. Y otra, la posición de la religión como manifestación de la aproximación de los hombres a lo sagrado y a la trascendencia frente al reto de la modernidad.

En muchos sentidos, el catolicismo se había mantenido incólume, hasta 1950, como una fuerza espiritual y moral en medio de la modernidad, pero que no parecía estar tocado por ésta, como factor de secularización y, más todavía, como una manifestación que provocaba incredulidad y escep- 
ticismo. En su versión próxima al ultramontanismo se había sentido como desafío frente a lo moderno. El Concilio Vaticano II, celebrado entre 1962 y 1965, bajo los pontificados de Juan XXIII y Pablo VI, suponía esa apertura ante lo moderno. Significó renovación y crisis, y una profunda modificación de la Iglesia en los países o comunidades donde el catolicismo había sido fuerte; el cambio fue más profundo en el pueblo católico. Con todo, se mantenía la perplejidad del catolicismo ante el dilema, que para muchos parecía excluyente, de transformar el mundo según el Evangelio; otros afirmaban que la mirada debería dirigirse privilegiadamente a la esperanza trascendental. Un extraño quietismo emanaba de la Iglesia en los años setenta, influyente en el mundo y a la vez separada por un velo de cristal.

Es en esta circunstancia que la aparición del Papa Juan Pablo II, arribado súbitamente por el fallecimiento primero de Pablo VI y, luego, por la inesperada y paralogizadora muerte de Juan Pablo I, vino a tener el efecto de un tónico de vigorización. El recibimiento por parte del pueblo católico al Papa polaco pasó de la sorpresa, e incluso de la extrañeza, a un entusiasmo por momentos delirante. Juan Pablo II desde un primerísimo momento desarrolló un estilo dinámico de líder religioso moderno, que a la vez tenía un mensaje milenario que guardar y del cual su oficio era ejercer el apostolado. De lo polifacético de su estilo hay que destacar unos rasgos evidentes.

El primero, los viajes como una forma de presencia apostólica. Logró atraer multitudes, ser escuchado, evocar temas morales y sociales como parte del debate público, y se convirtió en una referencia como figura pública mundial más allá del campo del cristianismo y del círculo cultural europeo. El viaje papal por la gran mayoría de los países del mundo constituyó un hito de su propia historia, independiente del efecto de golpe de vitalidad para el catolicismo local. Los viajes a EE. UU., a Polonia en 1979 o a México, en el inicio de su pontificado, para no hablar del efecto visible que tuvo en un Chile — hasta ese momento tan tenso - su visita en 1987, estrenaron este nuevo estilo que asumía la era de comunicación de masas sin verse absorbida por ella. Pío XII había adoptado los discursos radiofónicos como forma natural, pero fue una forma antes que un contenido. Con Juan Pablo II la forma y el contenido tienden a fundirse, aunque sea un fenómeno frágil y temporal.

Las giras del Papa polaco fueron la instancia de encuentro con el mundo. No obstante, hubo dos límites a la efectividad apostólica de estos viajes. En primer lugar, están ligados a la capacidad comunicacional de un hombre, Karol Wojtyla, que es difícil que se repita; los papas que le sigan no podrán imitar sin más a Juan Pablo II, so pena de caer en convencionalismos que han desgastado a las figuras públicas en el mundo secular. La 
distancia y cierto hieratismo eran elemento del atractivo misterio que rodeaba al papado. En segundo lugar, el paso del tiempo también dejó sus estragos en la persona del Papa, y los viajes llegaron a parecer un ritual que se cumplía por deber, por continuar por un camino abierto, y deslucía la actitud apostólica de comunicar un mensaje, de propagar el evangelio asumiendo transformadoramente el lenguaje de nuestros tiempos.

\section{Lo sagrado y lo profano}

Esto último es quizás la mejor herencia de Juan Pablo II. Desarrolló un lenguaje mediante una palabra sencilla, un gesto natural que también estaba provisto de espiritualidad, que sabía transmitir con su presencia en las giras, en las audiencias, en los documentos. Sabemos que las encíclicas son redactadas por equipos amplios, en los cuales puede resaltar el acento de un especialista destacado en tal o cual materia. En las de Juan Pablo II, quizás porque se le escuchaba tanto, a través de la lectura se puede oír la voz del mismo Papa. Sus homilías no tenían la construcción literaria y espiritualmente delicada de Pablo VI, pero ganaban en fuerza de acción y de mirada a la vida.

En sus giras, en su aproximación al mundo, puso énfasis en un catolicismo del "sí harás". Se alejó de la perspectiva más convencional, rutinaria, del "no harás". Quiso transmitir como actitud misionera esa imagen que lo llevó a ser tomado con respeto por líderes políticos e intelectuales, respeto por su autoridad moral, aunque no necesariamente compartieran todos los aspectos de la enseñanza de la Iglesia. Asumía la tarea de desarrollar una actitud y un lenguaje que entendieran y con-versaran (es decir, versación mutua) con el mundo surgido de la secularización, sin verlo como aberración y sin renunciar a la vez a los fueros de lo sagrado. El dilema entre el catolicismo (y, en general, las confesiones cristianas) y el mundo moderno puede ser quizás expresado en esta alternativa. La civilización occidental en su origen fue inseparable del sentimiento religioso y de la Iglesia. Fue en

- gran medida su misma dinámica la que hizo emerger la secularización, como creación de un espacio profano que no necesariamente se dirige contra la religión, pero que muestra una autonomía que puede ser radical, a veces en absoluta soledad.

Ha sido fuerte la tentación de proclamar "la muerte de Dios". También ha sido la tentación del sentimiento religioso definir a la modernidad como "pecado". La atmósfera mundial que rodeó al Concilio Vaticano II puso como modelo una apertura algo ingenua a la "verdad del mundo". Quizás todos confundían lo que había que dar a Dios y lo que había que 
entregar al César. El pontificado de Juan Pablo II exploró una nueva ruta, la de ponerse cara a cara ante el mundo secular y ejercer la sana tensión de la conversación, de la tensión creativa, de la distinción de esferas. El espíritu moderno, aquel que está abierto a la experiencia de lo sagrado, siente que se desliza por la cuerda floja de la autonomía y la libertad de preguntar, y de las nuevas perspectivas abiertas por la ciencia y la cultura. También tiene la conciencia de lo irreductible de la experiencia religiosa. La dualidad que envuelve esta tensión entrega riqueza a la vida. Enclaustrarse en una sola de ellas extingue un patrimonio del ser humano.

Terreno resbaladizo, donde el hombre moderno puede enclaustrarse en esa percepción de la "muerte de Dios", básicamente al considerar que la pregunta no tiene sentido porque no puede ser respondida. La religión sería un dato histórico. La fe del hombre moderno, en cambio, toma ese absurdo real como punto de partida para pensar de nuevo y experimentar en otro nivel la experiencia de lo sagrado y la apertura a la esperanza. Es aquí donde la palabra de Juan Pablo II ocupó un lugar destacado en la historia de la sensibilidad del catolicismo.

\section{La fuente: Derrotero trágico de Polonia}

Existen otras dimensiones de la vinculación de Juan Pablo II con la historia del siglo. El Papa polaco viene del país que ha sido uno de los casos más terribles de la tragedia del siglo XX. Después de las comunidades judías europeas, Polonia fue el país que más sufrió en la Segunda Guerra Mundial. El hecho más ominoso de la posibilidad negra del siglo, el pacto nazi-soviético del 23 de agosto de 1939, significó la esclavitud y cuasi exterminio del país en la guerra, y una existencia congelada en las cuatro décadas siguientes. En este sentido, el Colegio Cardenalicio escogió a un Papa "histórico" como pocos, por decirlo de una manera. Era el testigo de la persecución de la Iglesia y de su país. Polonia ha permanecido desde siempre como parte del corazón de Europa; además fue por siglos, junto a

Lituania, una isla católica encajonada entre los mares luteranos y cristianoortodoxos, ambos provistos de fuertes Estados que finalmente descuartizaran a la Polonia política en el siglo XVIII, aunque no a su sociedad y su cultura, no al menos hasta 1939.

Sobre la tragedia de la Segunda Guerra Mundial en Polonia es poco lo que se podría exagerar. El alzamiento de Varsovia en 1944, una de las grandes epopeyas del conflicto, terminó con su aplastamiento por los nazis \ y fue mirado con complicidad homicida por los soviéticos y abandonado 3ínicamente por los anglosajones. De ahí surgió una generación que, no 
siendo necesariamente comunista o marxista, creyó que era inevitable convivir con el nuevo régimen. Los mismos comunistas después de la muerte de Stalin fueron más moderados que otros de la entonces Europa Oriental. La Iglesia polaca, bajo la dirección del notable cardenal Wyszynski, tuvo una posición de independencia y aprendió a coexistir con el régimen. Todo este aprendizaje transpira en el despliegue del Papa Wojtyla y se vio en su tratamiento a la política mundial (incluyendo su influencia bienhechora por estos lares del Pacífico sur) y en general en el orden político de las sociedades.

Entonces, su elección fue también un rescate de la olvidada Polonia, mirada como parte de "Europa Oriental", olvidándose de su antigua unión con Occidente y su importante papel. A la elección de Juan Pablo II sucedió luego el estallido de Solidaridad en 1980, con Lech Walesa, y la evolución básicamente pacífica hacia el retorno a "Europa Central" de fines de los ochenta; y también la entrega del Premio Nobel en 1980 a una eminente figura de la poesía y del pensamiento del siglo XX, Czeslaw Milosz. Es imposible pensar a Wojtyla si no es como polaco. A la vez, ello no le dio un aire provinciano, sino que le permitió en sus años formativos pensar a Polonia y al comunismo (como a la sociedad occidental) más allá de ellos, y acometer una empresa por definición "universal”.

Su posición esencialmente crítica al marxismo era indudable, y se vio con claridad a lo largo del pontificado, pero esto no lo llevó a desarrollar una estrategia pontifical exclusivamente antimarxista. Desde un primer momento dijo en su círculo que consideraba al marxismo algo básicamente muerto. También aquí su mensaje no se limitó al "no”, sino que su objetivo esencial estuvo orientado a volver a instalar el mensaje de la Iglesia en la vida pública, llegando al hombre y la mujer individuales. Esta doble vertiente en su efectividad ha sido lo que ha distinguido a Roma en este último cuarto de siglo. Es lo que percibió nuestro país en los primeros días de abril de 1987. Era un lenguaje provisto de un nuevo vigor, que se apuntó a la afirmación de lo humano, al cual le es imprescindible la dimensión de lo sagrado.

\section{El Papa y la crisis del comunismo: ¿Causa y efecto?}

Se vincula al Papa con la caída del comunismo en Europa, y no faltan razones para ello. Sin embargo, hay que calificar esta afirmación. Existe ciertamente un lazo entre la elección de Karol Wojtyla como Juan Pablo II y la caída de los sistemas marxistas en la entonces Europa Oriental e incluso hasta en la misma Unión Soviética. El caso polaco fue siempre un eslabón débil en la estructura de poder de estos sistemas. Al revés de lo que habían 
profesado los ardientes patriotas polacos desde el siglo XVIII hasta la Segunda Guerra Mundial, a partir de 1956, tanto los líderes comunistas como los opositores (desde 1980) hicieron gala de moderación en relación con lo que era la situación del resto de los países comunistas. Milosz ha dicho que hasta los estalinistas de entre los polacos eran de un metal diferente del de los soviéticos, porque cultivaban una cierta liberalidad. Incluso en 1956, a raíz del sanguinario aplastamiento de la revolución anticomunista en Budapest, en Europa Oriental surgió una frase satírica: "Los húngaros se portaron como los polacos; los polacos se portaron como los checos, y los checos se portaron como los cerdos".

¿Qué existe de verdad en esta vindicta, aparte del humor negro y a todas luces injusto? Que para los polacos ya había pasado el momento del sacrificio heroico y sin perspectivas de victoria, sobre todo después del cuasi extermino biológico durante la Segunda Guerra Mundial. De ahí que se recurriera al acomodamiento como a la resistencia posible. A la vez, de entre todos los países del bloque soviético en la entonces Europa Oriental, en Polonia la sovietización fue menos radical. Esto tiene varias aristas. Por una parte fue el único país donde subsistió algún tipo de actividad económica privada, más que nada en el campo (en comercio, algo hubo en Hungría después de 1956), con un sector importante de la tierra en manos de medianos propietarios. Era un país cuyos habitantes tenían de manera consistente más relaciones con Europa Occidental y Estados Unidos. Es bien sabido el papel que el lobby polaco jugó en la política norteamericana en favor de los millones de descendientes de inmigrantes, que después de 1945 todavía eran un bloque bastante compacto.

Los mismos líderes soviéticos, Gomulka entre 1956 y 1970, y sobre todo Joseph Giereck, encarnaron ese comunismo (relativamente más liberal), en que aceptaban una cierta apertura en los viajes, en la tolerancia a la Iglesia y a cierta propiedad privada, con algunos ademanes poco importantes de independencia ante la URSS, todo dentro de una libertad de acción muy acotada. Con todo, los agricultores medianos no constituían una amenaza real al régimen. Era un grupo de interés y su sola existencia demostraba un "socialismo marxista incompleto", algo que no agradaba a los soviéticos, pero que tenían que tolerar.

El caso de la Iglesia católica, dirigida por la ya mencionada figura carismática del cardenal Stefan Wyszynski, constituía un verdadero poder paralelo. Es cierto que comparado con un sistema democrático, la Iglesia sufría restricciones. En el contexto de los sistemas marxistas, gozaba de 3 libertad de acción (relativa) y sus sacerdotes y dignatarios efectuaban constantes viajes al extranjero. Es allí donde el obispo y después cardenal Wojtyla pudo ejercitar su extraordinario talento de polígloto y hacerse co- 
nocido en la curia romana y por otros cardenales a lo largo del mundo. Esto no fue algo fortuito. Como se dijo, Polonia siempre fue una isla católica rodeada por dos océanos, uno germano protestante y otro ruso con la cristiandad ortodoxa. En este sentido, en Polonia y en Lituania, Iglesia y nación tendieron a confundirse, de una manera que quizás sólo se pude comparar con Irlanda.

Esto se acentuaría más con la pérdida de la independencia de Polonia, repartida entre sus vecinos desde la segunda mitad del siglo XVIII hasta 1918. Claro que en ese entonces el vivir bajo soberanía extranjera no implicaba un cambio social ni cultural. A veces el mismo Estado continuaba funcionando con algún tipo de fuerza armada y una administración que se podría considerar "nacional”, al menos en potencia. Había persecución a los intentos de rebelión política, especialmente en la zona más vasta, bajo soberanía zarista.

En cambio, en el siglo XX, la ocupación por las potencias totalitarias llevaba consigo un giro drástico y opresivo del orden social, el exterminio de vastos grupos sociales en el caso de la ocupación soviética, entre 1939 y 1945; en la zona nazi se podía proyectar un cuasi exterminio biológico de la población, sólo un grado menor que en el Holocausto. Y frente a ello, una gran tragedia, lo que se interpretó como una política arrogante de los polacos con su nueva independencia en 1918, y hasta imprudente. En los años 1930 esa política se expresó en la idea de que las dos potencias totalitarias no podían aliarse entre ellas. Eso fue lo que pasó el fatídico 23 de agosto de 1939. Y la lucha fue heroica entre 1939 y 1945, cuando la Iglesia estuvo en la vanguardia en darle una infraestructura de protección y comunicación al "Ejército del Interior", que obedecía al gobierno en el exilio en Londres. Pero los patriotas fueron sacrificados en el épico levantamiento de Varsovia, abandonados por los anglo-norteamericanos, que no hicieron gran cosa mientras los soviéticos observaron como los nazis exterminaban al "Ejército del Interior” en la ciudad entre agosto y octubre de 1944. Después avanzaron y tomaron la capital, y terminarían por instalar un gobierno títere.

La lección de estos hechos estremecedores fue que la pura rebelión armada ya se había agotado. Ahora había que ensayar otros métodos, aque¡ llos de la política, de saber que el enemigo totalitario, en el tiempo largo, tenía perdida la guerra, porque no representaba necesariamente el futuro. Además, bajo el sistema comunista no había alternativa, y no pocos polacos que detestaban al régimen consideraban que al menos respetaba la vida biológica del pueblo, aunque no su tradición ni sus posibilidades. De esta circunstancia surgió lentamente, bajo la férula de la dictadura comunista, al mismo tiempo una cultura política que en la práctica cultivaba la moderación, el acomodamiento, en el buen sentido de la palabra, y un cambio 
incremental. Hubo algunos levantamientos que culminaron en violencia, llegando la sangre al río, y que, para colmo de ironías, era fundamentalmente sangre de la "clase obrera", en 1956, en 1970 y, algo menos, en 1976. Las autoridades, hasta donde se sabe, no tenían estómago para una represión muy profunda y sanguinaria como la de Budapest en 1956. El uso de la fuerza, como en 1981, estuvo dirigido a impedir una intervención directa de la URSS. Ésta siempre amenazaba que "si no lo hacen ustedes, lo haremos nosotros”, como en Praga en 1968. Ésta era la cultura política en la que se movía el obispo y después cardenal Karol Wojtyla.

La Iglesia misma nunca dejó de estar bajo la presión policial y política del gobierno comunista, en un juego del gato y el ratón. Pero después de 1956 no se la perseguía a la manera de otros gobiernos del bloque soviético o de sistemas marxistas. La Iglesia, bajo el liderazgo del cardenal Wyszynski, constituía, como se dijo, una suerte de autoridad paralela, aunque "sin divisiones”, como fue el caso de Pío XII (de acuerdo con la mentada pregunta de Stalin a Roosevelt: “¿Cuántas divisiones tiene el Papa?”). De usarlas como partido político, por emplear una expresión, se hubiera desgastado en una competencia en torno a qué ofrecer. Aquí nos acercamos a la respuesta acerca del papel de Juan Pablo II en la caída del comunismo en Europa.

Su elección provocó un remezón considerable en toda Polonia —por la sorpresa del caso- y el reconocimiento que implicaba a la historia del país en la era moderna, con un tinte muy diferente a lo que se escuchaba en la doctrina oficial del comunismo. Para el gran público, y es de presumir que se debe integrar aquí al gobierno polaco, la elección fue completamente imprevista. Probablemente el Partido Comunista tenía la confianza de que los años mellarían la influencia de Wyszynski, quien estaba próximo a su retiro. Y que una nueva generación del alto clero no tendría la influencia de aquél. En círculos "progresistas” siempre se había asegurado que el caso polaco era una excepción, y que los sacerdotes jóvenes, se suponía en actitud de wishful thinking, serían más convergentes con el sistema, ya que se identificarían con ideales socialistas. Por cierto, había poco o nada de esto. De hecho, las autoridades comunistas confiaban en que podrían manipular al joven arzobispo y después cardenal, que estaría provisto de ambición, en contra del primado de Polonia. Por el contrario, el primado y el Vaticano promovían a esta personalidad innovadora, enérgica, trabajadora, porque reunía en sí dos virtudes que es poco corriente encontrarlas juntas. Por su trayectoria, tenía una raíz dentro del mundo obrero, y facilidad de acceso al pueblo católico, la gran fuerza originante del catolicismo popular polaco. Y mostraba además la capacidad intelectual para darle una proyección cultural mayor al catolicismo polaco. 
La experiencia como cardenal, al tratar con las autoridades comunistas, fue la semilla con la que destacaría su política hacia los sistemas marxistas. Llevó una actividad cotidiana, tenaz, de protestar contra cualquier atropello y exigir plenamente. En esto finalmente sería más activo que una parte del clero polaco, que aceptaba el acomodamiento con el régimen como "patriotismo". Ciertamente, no era el papel de la Iglesia promover la desestabilización del régimen, de ése ni de ninguno, salvo las consabidas reglas del “derecho de rebelión”. En 1968, al recordar los sucesos del siglo XIX, cuando la mayoría del país era parte del imperio ruso, decía que "los obispos y los sacerdotes jamás permitieron que la Iglesia se rusificara (...). La unidad entre la Iglesia y la nación siempre tuvo, y aún tiene, un significado fundamental para la nación y la Iglesia polacas”. O en 1973, al protestar contra una nueva ley en la educación, “porque no dice una palabra acerca de la sociedad cristiana, acerca de la contribución de Cristo, de la Iglesia y de la Cristiandad a la educación polaca”. Aunque estaba de acuerdo con la estrategia general de Wyszynski de coexistencia con las autoridades comunistas, quería ir más allá en la proclamación pública de la fe y de la cultura católicas, para no arriesgarse a ser una cara más de una Polonia estática. Más que una estrategia simplemente anticomunista, para estar más allá del comunismo debía ser una entidad viva en la sociedad. Nada había tampoco de un intento de identificación con una tendencia “progresista”.

\section{Elección, Solidaridad y crisis}

En Polonia la sorpresa de la elección del primado de Cracovia como Sumo Pontífice fue mayúscula, como en todo el mundo. Y de las primeras palabras de Wojtyla, ahora Juan Pablo II, no se escuchó nada que pudiera entenderse como una aproximación aunque fuese insinuante a un lenguaje progresista. Desde un primer momento, además de la imponencia del estilo, resaltó la espiritualidad de su mensaje, en alusiones a la "Virgen Negra" de Czestochowa. Y que viene de Polonia, “un país muy lejano” (en este fin de

mundo, no nos parece tanto). Y, en las referencias posteriores a su patria - natal, lo que se impone en el lenguaje papal es destacar el papel de Polonia como país católico a lo largo de toda su historia, en consonancia con la imagen, tan cara a los mismos polacos, de que representan a la Iglesia romana en un extremo de Europa. Esto nada tenía que ver con la historia oficial que se daba a sí mismo el régimen comunista, o con el papel que le había “asignado” Moscú en 1945. No era la "liberación” social lo que aparecía como el sentido de la historia polaca de los siglos XIX y XX, como era la tesis oficial, así como la había sido de los intelectuales marxistas, más que 
nada de los de antes de 1939. La tesis del nuevo Papa era que la fidelidad a Roma había sido la columna vertebral de la historia polaca. Éste sí que fue un mentís de partida a un régimen que había intentado sostenerse sobre una verdad ideológica con poca vitalidad, y sin creer demasiado en ella por lo demás.

El viaje de Juan Pablo II a Polonia en junio de 1979, el primero de todo un estilo pontifical, como se ha dicho, provocó revuelo internacional y conmoción en Polonia. No porque hubiera provocado desórdenes en esos días. La expresión de las multitudes apretujadas en todas partes demostró que la tesis poco creída, pero formalmente sostenida por el régimen, de que el socialismo (marxista) era la nueva realidad esencial de Polonia y el catolicismo una reliquia histórica, que se la "respetaba" por ser parte de la historia, porque el socialismo es tolerante..., que todo esto era la más pura falsedad. Era exactamente al revés, el socialismo del régimen constituía un cuerpo extraño, tolerado casi por inercia por la sociedad polaca. En cambio, el catolicismo y su Iglesia constituían símbolos vivos — como casi en ningún otro país de la tierra- del sentido de nación de Polonia. Lo que hubo de alma en el comunismo y el marxismo polacos había perecido en las mismas cárceles de Stalin en 1938, y no a manos del "fascismo" o de la "reacción”; había perecido en el pacto nazi-soviético; había perecido en las calles de Varsovia en 1944; había perecido en el pantano de la vida conformista bajo la "democracia popular". Había sido algo vivo en el período de entreguerras; el mismísimo Czeslaw Milosz lo había representado de cierta manera; y, como se dijo, después de Yalta muchos creyeron que la supervivencia biológica de los polacos sólo se podía garantizar en la colaboración con los soviéticos.

$\mathrm{Al}$ dirigirse a una multitud en el centro de Varsovia, Juan Pablo II dijo que nadie entiende a esa ciudad si no sabe que en la Segunda Guerra Mundial se alzó contra el ocupante y que perdió 200 mil de sus hijos e hijas, siendo abandonada por sus aliados. Los periodistas occidentales pensaron que era una alusión a la URSS; pensamos más bien que se trató de una velada crítica a los aliados occidentales, por no haber hecho casi nada por asistir a los alzados del "Ejército del Interior". En fin, para lo que aquí interesa, las palabras del Pontífice daban otro rotundo mentís a la historia oficial de que el alzamiento había sido una "provocación” de los reaccionarios. Esto no era sólo una curiosidad histórica, sino que tocaba el fundamento de la legitimidad del sistema. La "historia oficial" era inherente a sus cimientos.

Mas el Papa no había concurrido a Polonia a derribar a las autoridades comunistas. Si ésa hubiese sido su estrategia, simple y llanamente 
querría decir que a la Iglesia habría que juzgarla por su efectividad, o "productividad”, en el cambio político; o, ¿por qué no también en el "cambio social”? Sería un simple poder terrenal. La religión que se "realizara” dejaría de ser religión. Ya se volverá sobre esto. No cabe duda de que a la situación de crisis latente del régimen comunista la elección del Papa le dio un combustible extra. Polonia parecía súbitamente reivindicada no sólo a sus propios ojos, sino que foco de la atención mundial. Cuando el régimen quiso llevar a cabo un "ajuste" para enmendar las fallidas reformas de los setenta, vino la reacción, que no se canalizó a partir de la clase media sino que por la "clase obrera", en los astilleros de Gdansk.

En pocos días, el aire de revuelta pacífica se esparció por todo el país y a la mayoría de los sectores. Además, se formó de facto un actor político, el sindicato Solidaridad, y un caudillo, Lech Walesa, y en los hechos Polonia pasó a ser una sociedad políticamente pluralista. El gobierno entre que no se atrevió y ya no tenía la voluntad de emplear la "violencia legítima”, entre otras razones, porque era más civilizado que sus antecesores. A continuación cayó Giereck, y fue sucedido por una serie de líderes contemporizadores, hasta que finalmente ocurrió lo previsible, que ante el virtual desgobierno se acudió al ejército, a cuya cabeza estaba el general Wojciech Jaruzelski, teóricamente comunista. El fantasma que rondaba era el de una ocupación soviética, que sería algo más duro que el aplastamiento de la Primavera de Praga en agosto de 1968. Tanto la gran mayoría de los líderes del partido como los militares querían evitar esta situación. Es posible que hasta los soviéticos estuvieran asustados de esta perspectiva. La existencia de un Papa polaco en Roma, convertido rápidamente en una figura de la política mundial, era un obstáculo formidable para la idea de que una invasión sería "un paseo".

Bueno, ¿qué papel tuvo en todo esto Juan Pablo II? No es fácil responder esta pregunta, si es que se está pensando en una cadena de causa y efecto. Polonia fue siempre el plato más indigerible para Moscú de todo el sistema soviético. Pero su sintomatología se hallaba en el resto del sistema; y desde 1956, como se decía, Polonia había gozado de "privile- gios”, que sin embargo ahora también los demandaban otros países del bloque. En una suprema ironía de la historia, Moscú era ahora dependiente del régimen comunista de Berlín Este, y estaba claro que cada día que pasaba tenía que negociar con sus "satélites" la estabilidad del sistema. En los años finales de Brezhnev (1964-1982) esto era una agonía para el Politburó moscovita. En este panorama, fue evidente que la presencia de Juan Pablo II en primer lugar acentuó, aunque no creó, una atmósfera de inestabilidad en Polonia, al concentrar la atención internacional en el país y darles a Walesa y a Solidaridad la sensación de no estar aislados. En segundo lugar, hacía 
bastante más complicada una presunta intervención soviética. Después de Afganistán y del derrumbe del marxismo intelectual en Europa, la reacción internacional podía ser catastrófica en términos políticos. Con todo, los procesos y los actores principales se habían puesto en marcha en el curso de los años 1970, antes del ascenso de Karol Wojtyla al pontificado, aunque ciertamente la Polonia católica había sido un motor del cambio pacífico.

Esto se aclara más si se examina brevemente el decurso de los hechos hasta la caída final del comunismo en Europa. Hoy nadie duda de que el "golpe" del general Jaruzelski, el 13 de diciembre de 1981, con el cual suprimió la disidencia al comunismo e impuso una rígida dictadura militar, fue un recurso extremo frente a la alternativa de una invasión soviética. Decimos dictadura "militar" y no "comunista" porque precisamente la proclamación de Jaruzelski, rodeado de figuras uniformadas, exhalaba el mismo lenguaje de las juntas militares latinoamericanas de la segunda mitad del siglo XX, en referencia a la "salvación nacional" y a la "patria en peligro". Salvo una frase inevitable de cortesía, no se hablaba ni de lucha de clases o de proletariado, nada que recordara la retórica del sistema marxista. Quizás éste fue uno de los momentos cruciales del fin de la apelación de la ideología marxista.

La reacción occidental y especialmente norteamericana a estos sucesos fue muy dura, en términos puramente políticos, eso sí. En cambio sorprendió que el Papa no se pusiera en una línea confrontacional. Realizó todavía dos viajes más a Polonia, en 1983 y 1987, en las condiciones de un país semiparalizado por el desgano y el estancamiento, aunque no se pueda decir que haya sido un gobierno sanguinario ni mucho menos. Simplemente marcaba el paso. No faltó quien en Polonia y en otras partes se sorprendiera por la aparente escasez de belicosidad de Juan Pablo II ante el golpe de Jaruzelski.

Era sencillamente que la "inacción papal” tenía profundas raíces en la historia de las relaciones de la Iglesia con el poder temporal. No era su papel ponerse a derrocar gobiernos, por comunistas que fuesen. Además, Juan Pablo II estaba perfectamente consciente de que no trataba con un gobierno estalinista, y que la situación concreta de los polacos no mejoraría empujándolos a una confrontación irracional. Una negociación discreta y empujar las cosas hacia un acuerdo posible, para restituir algo de libertad de movimiento a Solidaridad (la Iglesia la tenía desde hace tiempo), era esencial para un desenlace más o menos feliz, cuando todavía no se sospechaba de la crisis en la URSS.

Desde luego, en la cuestión de ¿cuándo es legítimo intervenir? se orilla un problema y una ambigüedad esenciales en la relación de la Iglesia y del poder político. En el asunto del tiranicidio llega a su culminación. Se 
trata de un asunto espinudo en la historia del catolicismo. Pero ha llegado a ser el corazón de debates contemporáneos en relación con el comportamiento del Vaticano ante el Holocausto. No es éste el lugar para tratarlo, salvo señalar que el marco en que debe ser interpretado es justamente el del papel de Roma ante los grandes procesos políticos. Creemos que, con sabia sensatez, primero el cardenal Wojtyla supo dar una nueva estrategia desde Cracovia. Después, Juan Pablo II supo dar un mensaje que estaba más allá del comunismo, y que no era de suyo identificable con el antimarxismo político, aunque suponía una crítica radical a las ideologías totalitarias. Por ello adoptó una actitud más bien de intermediario en la disputa dentro de Polonia. No se trataba de legitimar al régimen, pero tampoco de socavarlo sin pensar en las consecuencias. Cuando Varsovia fue la primera capital en expresar el cambio en junio de 1989, al nombrarse a un representante de Solidaridad, Tadeusz Mazowiecki, como Primer Ministro, sólo se sellaba la suerte del régimen comunista. Luego, en los meses siguientes a partir de fines de octubre, se desmoronó en jornadas célebres, pacíficas (salvo en Rumania), todo el resto del sistema; y la transformación de la URSS seguiría su proceso hasta fines de 1991.

Y no faltó el colofón. Después de la caída del comunismo, en Polonia y en las zonas católicas de los países del ex bloque soviético, la Iglesia y el catolicismo han debido sufrir todos los embates de la modernidad antes reprimida. En la misma Polonia, la posición de la Iglesia no concita esa adhesión como legitimidad nacional, al menos no en el mismo grado que antes. Ciertamente, su autoridad es y será mucho más fuerte que en la mayoría de los otros países europeos católicos. Mas los desafíos profundos de la modernidad no venían exclusivamente del marxismo o de persuasiones análogas, sino de la necesidad de la Iglesia de incorporar el reto de la modernidad. Eso lo comprendió certeramente Juan Pablo II.

\section{El Papa y la Providencia}

En todo esto ¿qué papel le tocó al Papa? ¿Fue él quien logró el fin del comunismo? Por supuesto, el asunto no es tan sencillo. Fue decisivo para el fin del comunismo en Europa el proceso de desgaste en la URSS; esto es lo esencial. Sus líderes, entre circa 1987 y 1990, experimentaron un espectacular cambio de paradigma, desde el marxista, tal como fue creado a partir de 1917, hasta el "modelo occidental", es decir, aquel de sus adversarios. Como los conflictos básicos del siglo, a partir de 1917, habían consistido en una combinación de lucha de estados y luchas de creencias o ideologías, la 
“estructura” de la Guerra Fría cayó por su base. En la deslegitimación del marxismo y después del bloque soviético estuvieron comprometidas muchas fuerzas y actores, no pocas veces contradictorios entre sí. La persistencia de la religión fue una de ellas. La revaluación del vínculo entre religión y orden social, que incluyó la aparición del fundamentalismo islámico y, en potencia, del de otras religiones, fue un fenómeno visible a partir de los años setenta. En sí misma, esa revaluación implicaba un asalto imparable a la lógica del marxismo, y de los sistemas en ella inspirados, de ser la lectura correcta de la cadena inexorable de la historia.

Es cierto que en Europa Occidental esto no se dejó ver, pero sí en las otras regiones del globo. En Europa Oriental —en la que muy luego se volvería a distinguir una "Europa Central”- - lo que llamó la atención fue la supervivencia de la religión, y que no había sucedido la extinción del "opio del pueblo". En Polonia, como se ha dicho, la Iglesia y la figura de Juan Pablo II fueron de primera magnitud, aunque no se puede sostener simplemente que "el Papa haya terminado con el comunismo".

¿Por qué sería significativo decir que Juan Pablo II fue la causa del fin del comunismo? Para un creyente, nos atreveríamos a afirmar, ello no es sustancial. Cierto, aquí rozamos el difícil y, finalmente, insoluble misterio de la intervención providencial en la historia. No pocas veces, desde una actitud de beatería arrogante, se asume que "no es buen católico" el que llegue a poner en duda que "el Papa terminó con el comunismo". Y no sólo porque algunas de las consecuencias del marxismo, para hablar más generalizadamente, van a seguir por mucho tiempo con nosotros, no es útil ni sabio asumir sin más esa afirmación. Aquí existe un gran equívoco en la visión del providencialismo.

Se dijo poco antes que no era el papel de la Iglesia el construir o derribar sistemas políticos. La piedad cristiana podrá inspirarlos; en cambio la pretensión de "inventarlos" se condensa en los cimientos del palacio del "Príncipe de este Mundo". Si existe un acontecimiento positivo, se lo concedemos a la Providencia; ¿qué se podrá afirmar del siglo de la guerra total y del exterminio genocida? Esta ruta nos llevaría por los caminos equivocaU dos. Un cristiano deberá afirmar una visión providencialista de la historia, pero no para cantar las metamorfosis intramundanas. Para el creyente, al fenómeno histórico le es inherente una teleología; la implicancia concreta, terrenal de ésta, le es en cambio inescrutable. Sólo la fe le permite mirarla y confrontarla como resbaladiza decisión moral en cuanto persona individual, que debe asumir en su situación cotidiana, insuficiente de suyo, y que siempre está acechada por el fracaso y el error, mientras que tras una densa capa de niebla brilla la esperanza redentora. Lo último que podría servir a 
este sustrato del ser humano es interpretar su situación como herramienta para legitimar un poder o para emprender un salto que opere en el "cambio social” como religión "realizada".

\section{Más allá de (todas) las ideologías}

Algunas críticas más o menos abiertas trataron de identificar a Juan Pablo II con lo que se llamaba "nueva Guerra Fría”, a comienzos de los ochenta. Supo evadir esas trampas cautivantes, sin dejar de dar la palabra oportuna. Y saltó con claridad al mundo de después de la Guerra Fría con la notable Encíclica Centessimus Annus (1991), para caer de lleno al mundo de lo vertiginoso de nuestros tiempos y mantener la imagen religiosa y moral en los años de crisis de lo público. Aunque la edad y la pesantez de toda organización gigante fueron factores de erosión, Juan Pablo II rescató la gran virtud histórica del catolicismo, una capacidad no sospechada de reinventarse a sí mismo. Su último viaje a México en 2002, en medio de las tempestades por ondas sísmicas, sobre todo de la poderosa Iglesia norteamericana, mostró esas virtudes. Al final, de todas maneras, los hombres tienen un límite, y el corazón humano de la Iglesia se encamina a ver cómo confronta los desafíos del siglo XXI.

El papado tuvo un éxito destacado en reforzar la labor de la Iglesia en gran parte del mundo. Al ponerla más consciente de su misión, le dio más seguridad en sí misma. También la Iglesia siguió la senda de una mayor centralización y purificación. La Iglesia, en cuanto organización, quizás nunca fue más pura que en el siglo XX. Más pequeña en número de sacerdotes, la motivación era más fuerte y los obstáculos mayores, aunque siguió manifestando una tensión de incertidumbre en los tratos con el mundo secular. También la concentración en torno al liderato de Roma ha quitado diversidad. La manifestación que se identificó con la "teología de la liberación" casi desapareció. Cierto que nunca tuvo mucho "pueblo", aunque sí logró conmover a gran cantidad de sacerdotes. La Iglesia dejaría de ser tal si se identificara decisivamente con esa perspectiva; para que sea Iglesia tamj bién debe dar cabida a la postura socialmente transformadora, como una de sus caras. Asimismo, se pierde otra parte de sí misma al haberse (auto)marginado la Confraternidad San Pío X, una de las versiones del tradicionalismo, contrapunto de la anterior y ancla necesaria en la vorágine del cambio.

3 Por último, hubo un terreno donde las cosas quedaron más o menos igual, en Europa Occidental, donde no se han visto signos evidentes de reconversión. Éste es un desafío tan grande como el futuro espiritual de 
África negra o la ofensiva audaz del fundamentalismo islámico. Como ya dijimos, en la misma tierra del Papa, en su Polonia natal, y en esa Europa que estuvo bajo el comunismo, después de la caída de este último, el catolicismo parece que deberá pasar por toda la ordalía de la secularización antes de ver el papel definitivo de la Iglesia. Con todo, aquí parece que la reconversión sí tiene un futuro.

\section{Líder espiritual a fines de siglo}

El Papa polaco le dio un nuevo brillo a la función apostólica, y un sentido de misión y propósito al cuerpo organizado de la Iglesia. En tiempos de crisis de líderes, que no es sino otro aspecto de la "crisis del sujeto", Wojtyla, transmutado en Juan Pablo II, le dio un propósito y un sentido a la actividad apostólica. La Iglesia era de nuevo gobernada. Si nos ponemos por un momento en la circunstancia de fines de los setenta, vemos que había sensación de falta de liderazgo en el mundo, salvo el de unos pocos líderes revolucionarios en la penumbra. Los sistemas marxistas parecían fuertes, aunque estaban no muy lejos de caer en el colapso. Una vez desaparecidos los líderes de la posguerra, los nuevos dirigentes podrían haber sido eficaces, pero en la política moderna no irradian el aura moral que se asociaba al gran estadista. Y, aunque es más bien tema de nuestro tiempo, lo mismo llegó a la figura del "intelectual público", y las figuras más mediáticas, como el Dalai Lama, están integradas a una cultura "New Age”, de acceso limitado para el hombre y la mujer comunes y corrientes.

Fue en este panorama donde Juan Pablo II irradió liderazgo no sólo dentro de la Iglesia, sino que como un punto de referencia mundial, más allá del mundo católico y cristiano, más allá de la tradicional influencia del Vaticano en las relaciones internacionales. Esto hizo que sus giras fuesen, más que apostolado católico, una referencia total de la cultura de nuestro tiempo. La misma experiencia se reforzó después de la Guerra Fría, cuando el "triunfo de la democracia y de la economía de mercado" no parecía un programa lo suficientemente inspirador como para fundamentar la política del futuro. Nuevamente fue el Papa Wojtyla quien se convirtió en la fuente de recuerdo de una dimensión mayor de los asuntos públicos.

\section{Lo arcaico y lo moderno: Presencia de la religión a fines de siglo}

Existe otra dimensión histórica de Juan Pablo II. Hay una coincidencia entre su elección y la renovación, a veces políticamente sísmica, de otras experiencias religiosas. Había sido un supuesto de muchos sectores que la 
modernidad iría enfriando la fe religiosa hasta que ésta llegaría a ocupar un puesto más o menos limitado en la vida del hombre, si acaso no se extinguía. Religión y modernidad parecían casi antinomias.

Se ha visto cómo a partir de 1978 la Iglesia tuvo una respuesta con el nuevo Pontífice. Si se mira con atención, ese año parece un punto de inflexión, aunque no todo permita ser optimista. Una cosa empezó a verse claramente: que la religión era también una parte de la modernidad. El pontificado le dio a la Iglesia un dinamismo que lo abrió a la esperanza de renovar no sólo al mundo católico, sino que de ir más allá de sus fronteras, aunque también hay que ver los límites que esto ha tenido.

Ese mismo año el mundo se conmovía con el inicio de la revolución iraní y ese fenómeno, el fundamentalismo islámico, que aparecía tan salido de los recodos de un pasado remoto. Se trataba además de un impulso religioso que iba por el camino contrario al del catolicismo (y al del cristianismo en general) moderno, en su propósito fanático de identificar fe y poder a todo trance. Creó el primer Estado teocrático moderno. Es ciertamente un desafío a las confesiones cristianas, y en parte les es furiosamente hostil. Por lo demás, se ha visto un retorno de algunos fundamentalismos protestantes, aunque en un contexto de la sociedad abierta, como algo similar en el mundo judío, que no deja de poner leña en la hoguera del conflicto de Medio Oriente. Algunos católicos se entusiasman con el fundamentalismo islámico y lo ven como manifestación de fe en Dios, que por cierto lo es. Hay que apuntar que en el ser humano hay una condición que hace que toda expresión de una disposición central a él, por elevada que sea, si es tomada como actitud monomaníaca, y encima impuesta como programa de cambio de la sociedad, se vuelve en lo contrario de su propio postulado. Esto es lo aterrador de cualquier fundamentalismo.

En otro sentido, el fundamentalismo pone el dedo en la llaga en cuanto la religión no es un fenómeno crecientemente marginal, sino que quizás es un componente más, pero también fundamental, de la modernidad. En la medida en que ésta consiste en cambio vertiginoso, incesante, debe anclar en un pasado remoto, primigenio, fundante. Por algo a la vanguardia le corresponde también su elemento arcaizante.

El legado de Juan Pablo II fue haber cerrado creativa y esperanzadoramente el ciclo abierto por el Concilio Vaticano II. Las tareas del nuevo pontificado estarán vinculadas a este proceso de largo plazo, de las tensiones y de las relaciones mutuas y fecundas entre el mundo secular y su diversidad a lo largo del mundo, y el ancla estará en la experiencia sagrada, tal como ha sido transmitida por la Iglesia romana. 